\title{
Renovation the Physical Characteristics of Aged Bitumen Using Vacuum Residue
}

\section{Abdulbasit Abdulaziz 2 Muhmood,Halah Abdulsattar Dawood}

1-Assist professor Northern Technical University, Mosul, Nineveh 41001, Iraq

2- Post Graduate Student, Dept of building and contraction Engineering

,Technical college, Northern Technical University, Mosul, Nineveh 41001, Iraq

\begin{abstract}
For most countries, the use of recycled asphalt pavement (RAP) has become increasingly common practice as it is both an environmentally and economically desirable option. The aging of bitumen throughout Stocking, blending, transporting and placement on Ways And even service life, the much more severe issues presented through the use of bitumen for pavements. This Research explores A potential of using vacuum residue oil as an effective Rejuvenation agent for aged bitumen, which is a by-product of a condition identical to the original bitumen. As the control binder, Bitumen with Pen 50-60 was selected. At different concentrations, vacuum residue oil was added0 percent, 2.5 percent, 5 percent, 7.5 percent and 10 percent respectively by weight of the total binder in aged bitumen at different concentrations Including penetration, softening point, penetration index ( PI), the features of the renewed bitumen have been tested. As the VR concentration increased Both binding time and temperature were strongly dependent on the ability to merge Of the aged,Virgin Binders. Reduced mixing temps Decreased diffusion of virgin bitumen and aged binder.
\end{abstract}

\section{Introduction}

A concept that translates to extracted and/or reprocessed asphalt and aggregates is reclaimed asphalt pavement (RAP))[1]. Current asphalt surface materials are usually extracted during resurfacing, renovation or reconstruction programs. When extracted and refined, RAP, which includes an useful asphalt binder and aggregate, becomes a pavement material.[2] From the year 1915, the very first RAP was used to create a new road structure and to enhance the strength of the road. The use of new aggregate and virgin asphalt binders is minimized by using RAP. However, due to stiffness and workability problems, the use of RAP is limited. RAP has become an extremely desirable option because it preserves resources and is environmentally sustainable.[3] By use of RAP also lowers power usage, decreases transport costs needed to obtain natural aggregates quality and saves land. In addition, the volume of construction and demolition waste placed in landfills is limited using RAP. Recycling asphalt effectively produces a chain that minimizes the use of natural resources and benefits the asphalt paving industry. 
[4] Even so, within the bituminous mixture, RAP incorporates some negative effects, some of which derive from the brittleness arising from the initial pavement's aging. Generally, the aged bitumen that has been used in RAP is marked by a greater softening point and reduced ductility and penetration rates, both of which, compared to virgin asphalt, lead to reduced cohesion and adhesion features.[5] if effective, asphalt pavement reuse results in a substance with properties comparable to those of the typical bituminous mixture. [6]

The traditional method for restoring the old bitumen properties of the new (virgin) binder is to rejuvenate the aged asphalt binder. The rejuvenating additive has become one of the recycling agents and is suitable for either highly oxidized mixtures or higher RAP (more than 25\% RAP) or recycled asphalt shingles (RAS) mixtures.[7] The aging method can be categorized into the short-term aging phase that happens during the project construction and the long-term aging phase that exists over the service life of the pavement. The form and dose of a rejuvenating agent must be selected according to the degree to which asphalt binder properties can be enhanced.[8] Finished / recycled binder homogeneity is a major factor that usually relies on manufacturing parameters ( e.g. mixing rate, mixing time), type of production equipment, RAP introductory process, and kind of new binder or rejuvenating agent. [9]

The much more important effect of rejuvenating agents mostly on fatigue performance of RAP mixtures was demonstrated in a research report. Compared to the 30 per cent RAP mix without additives, the 30 per cent RAP mix, which had a VR fraction as a rejuvenator, had exceptionally good fatigue performance. In reality, the fatigue output of this rejuvenated RAP mixture was similar to the $15 \%$ RAP-only mix, showing that the use of rejuvenating agents will enable higher RAP quantities to be used without compromising the RAP.[10] Research conducted by Zaumanis et al.[ has evaluated effectiveness for Rejuvenating additives in the processing of 40-100 percent RAP mixtures. variety of softening additives, including waste derived oils, plant oils, base oils from refineries (both non-traditional and traditional) and engineered oils have been used. In addition, waste engine oil (WEO), WEO bottoms, WEO with FT wax, distilled tall oil, naphthenic flux oil, organic mix, aromatic extract, refined tallow, were the rejuvenating agents Base oil and paraffinic oil. Every rejuvenating agent had a contrasting effect upon this aged asphalt binder, , the findings have shown. The refined sulphur was the most effective in reducing the viscosity of the RAP binder. WEO bottoms, nevertheless, were linked to higher level of viscosity, indicating that they gained higher compaction and mixing of temperatures. In the study, the authors also recorded performance measurements at low temperatures, the aim being to assess indirect compliance to tensile creep as well as indirect tensile strength. Rejuvenating agents also improved their low temperature characteristics of mix in almost all situations.[11] 
Vacuum residue oil was being used in research to restore the amount of asphaltenes / maltenes for their Initial form of an aged binder, (VR) is a very rigid type of bitumen Supplied from a plant fitted with a petroleum cocker (process known as coking) that operates a vacuum distillation process.the Coking is performed during the refining process to extract some of the light fractions of crude oilSofter fractions are used in the processing of items of greater Economic importance, such as petrol and other oils. As oil prices rise, gasoline and jet fuel price increases, providing more incentives to increase the production of lighter fractions of refined petroleum. Typically, VR can not be used for paving due to loss of lighter fractions (saturated fractions) in the VR, that leaves it very rigid. [12]

Seyyed Bagher et al . (2010), by incorporating different Recycled materials polymers including non-polymer materials without air blowing VR, examined the risk of penetration of modified bitumen from vacuum bottom residue (VR). The findings revealed a mixture of $10 \%$ raw bitumen with $5 \%$ recycled latex. with VR is ideal for changed 60/70 grade bitumen with enhanced rheological activity and thus minimized the risk of cracking at low temperatures and rutting at high temperatures.[13]

Materials and Experiments

1- Materials: virgin bitumen, aged bitumen, and VR is used

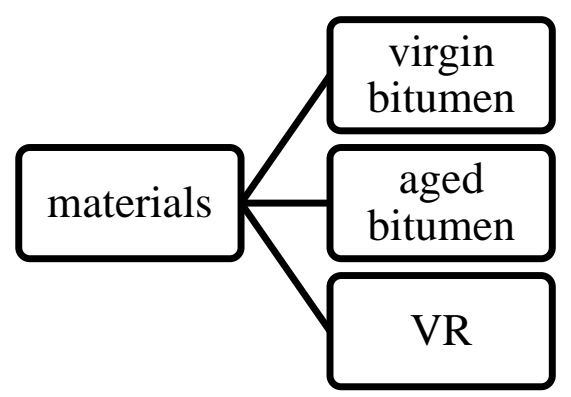

\subsection{Virgin Bitumen}

The control binder being used is Penetration . 50-60 bitumen provided from of the Qyara oil refinery, Table 1 indicates a range of physical Attributes for bitumen used.

\begin{tabular}{|c|c|c|}
\hline Properties & Virgin Bitumen & ASTM Specification \\
\hline 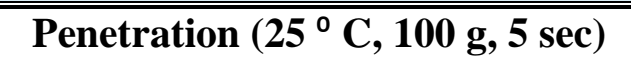 & 54 & D-5 \\
\hline Ductility $\left(25^{\circ} \mathrm{C}, 5 \mathrm{~cm} / \mathrm{min}\right)$ & 133 & D-113 \\
\hline Softening point (ring \& ball) & 60 & D-36 \\
\hline Flash Point (Cleveland Open Cup) & 274 & D-92 \\
\hline Specific gravity at $25^{\circ} \mathrm{C}$ & 1.039 & D-70 \\
\hline Viscosity @ $135{ }^{\circ} \mathrm{C}$ (mPa.s) & 450 & D4402-15 \\
\hline
\end{tabular}




\begin{tabular}{|c|c|c|}
\hline Viscosity @ $165^{\circ} \mathrm{C}$ (mPa.s) & 187 & D4402-15 \\
\hline
\end{tabular}

Table 1. Attributes of virgin bitumen

\subsection{Aged bitumen}

RAP where taken from Mosul-Dohuk high way, and it was prepared by first is the extraction process, second the distillation process. table 2 indicates a range of physical Characteristics of the aged bitumen produced.

\begin{tabular}{|c|c|c|}
\hline Properties & Aged Bitumen & ASTM Specification \\
\hline $\begin{array}{c}\text { Penetration }\left(25^{\circ} \mathrm{C}, 100 \mathrm{~g}, 5\right. \\
\mathrm{sec})\end{array}$ & 24 & D-5 \\
\hline Ductility $\left(25^{\circ} \mathrm{C}, 5 \mathrm{~cm} / \mathrm{min}\right)$ & 80 & D-113 \\
\hline Softening point (ring \& ball) & 56 & D-36 \\
\hline Viscosity @ $135{ }^{\circ} \mathrm{C}$ (mPa.s) & 2600 & D4402-15 \\
\hline Viscosity@ $165{ }^{\circ} \mathrm{C}$ (mPa.s) & 840 & D4402-15 \\
\hline
\end{tabular}

Table 2. properties of aged bitumen

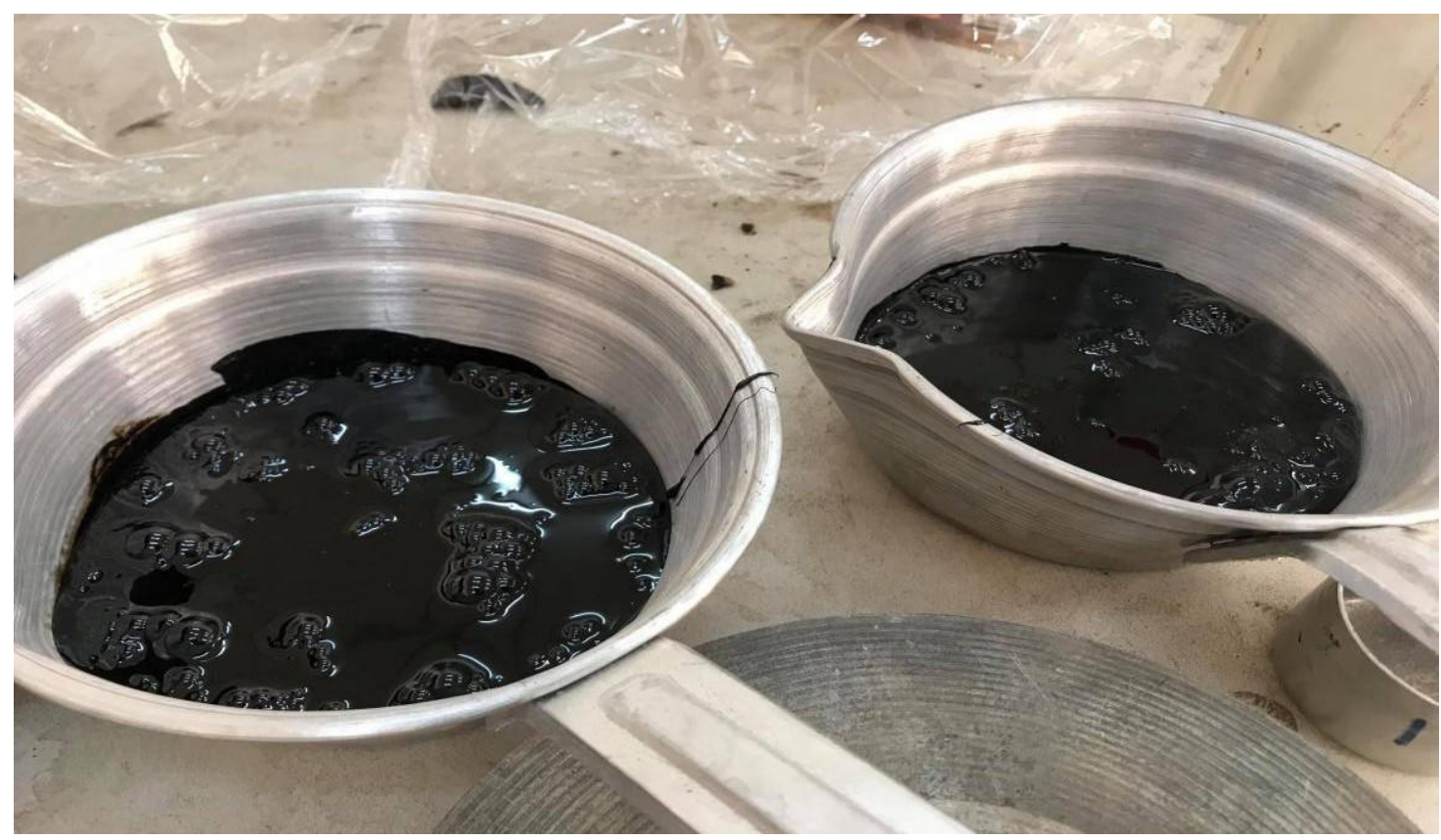

aged bitumen 


\section{3 vacuum residue oil}

\begin{tabular}{|c|c|c|}
\hline \hline Properties & VR & ASTM Specification \\
\hline Penetration $\left(25^{\circ} \mathbf{C}, \mathbf{1 0 0}\right.$ g, 5 sec) & 155.6 & D-5 \\
\hline Density @ 20 ${ }^{\circ} \mathbf{C}(\mathbf{k g} / \mathbf{c m 3})$ & $\mathbf{0 . 0 4 8 8}$ & D-70 \\
\hline Flash Point (Cleveland Open Cup) & 210 & D-92 \\
\hline Viscosity @ $135{ }^{\circ} \mathbf{C}$ (mPa.s) & 250 & D4402-15 \\
\hline
\end{tabular}

Table 3 . properties of vacuum residue oil

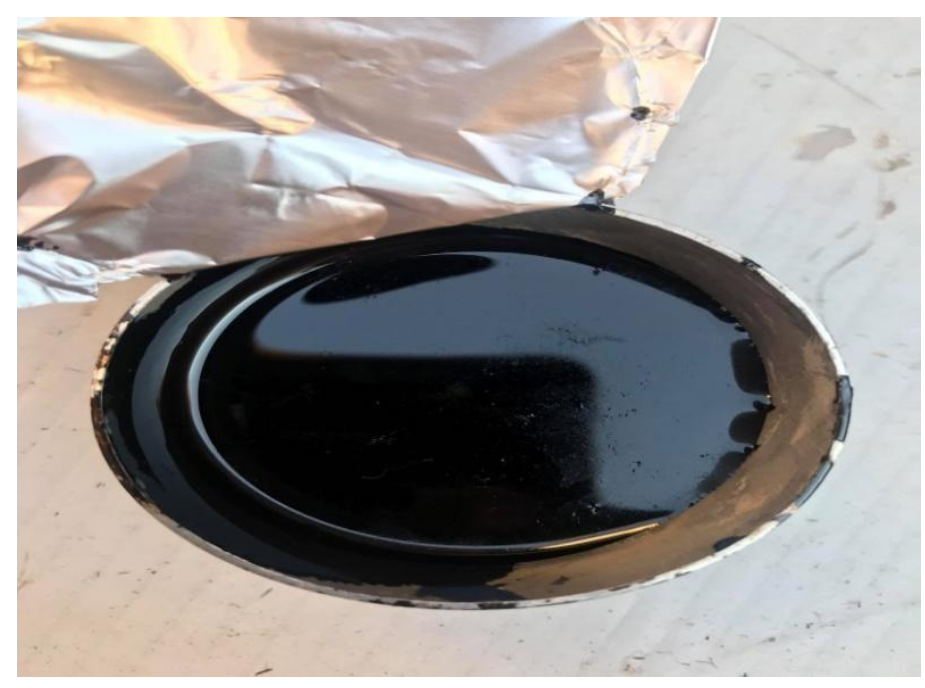

figure 1. vacuum residue oil

\section{2- Preparation of aged bitumen}

The preparation of aged bitumen is done by two stages, first is the extraction process, second the distillation process.

\subsection{Extraction process:}

For the sourcing of RAP from Mosul-Dohuk freeway with a life of service approximately 20 years, a milling process was carried out. As per ASTM D2172, Figure 2, showing the specifics of the extraction process. The RAP bitumen were collected via methylene chloride solvent. [14] 


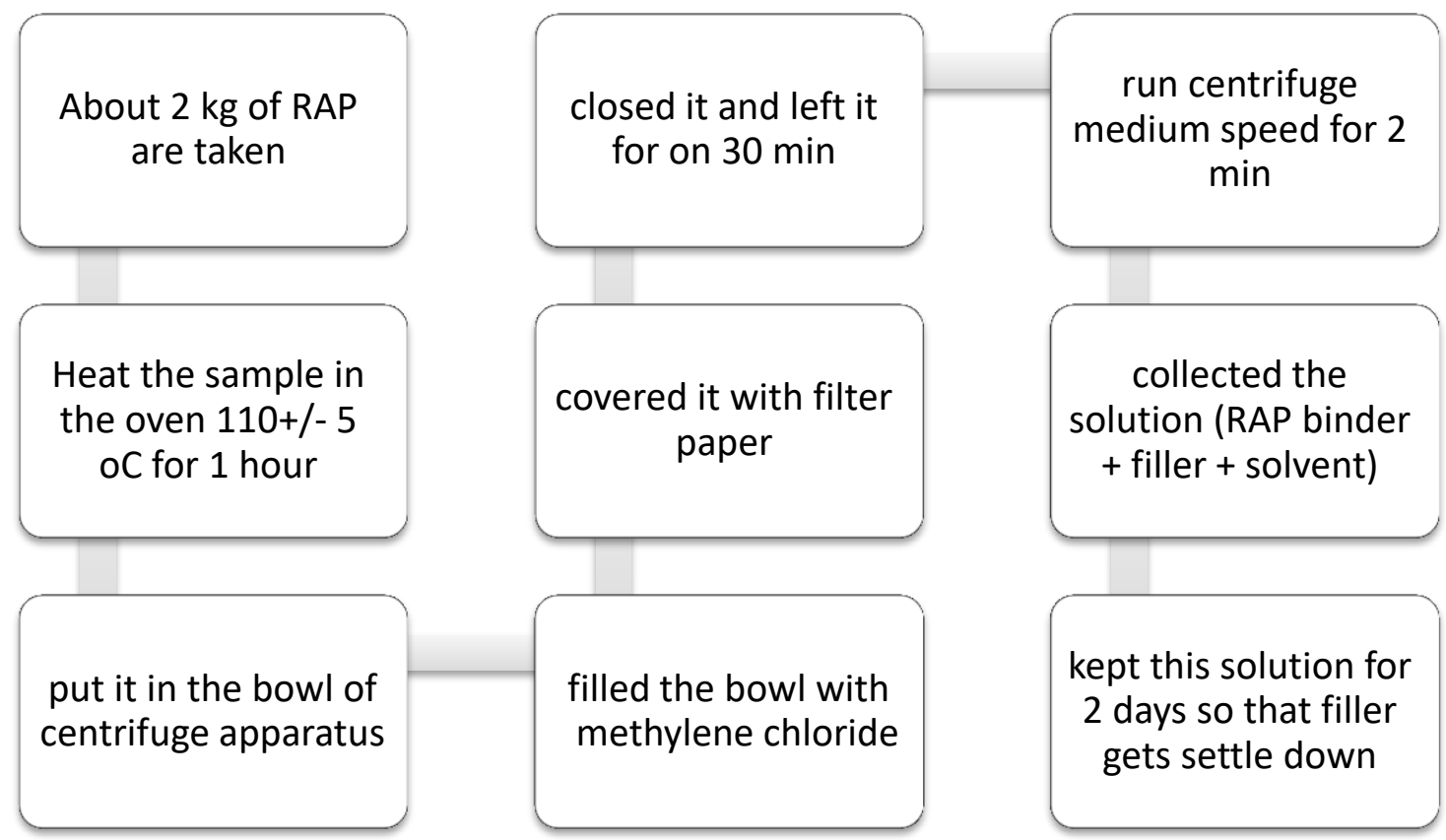

Figure2. extraction process

\subsection{Distillation process:}

The distillation apparatus is then used, as per ASTM D5404, for evaporation of methylene chloride and Restore the old bitumen. The method involves adding the solution inside of the flask, turning the heat on until it reaches $50{ }^{\circ} \mathrm{C}$ for 2 hours, then gathering the aged bitumen. The specifications of the distillation system are shown in figure 3.[15].

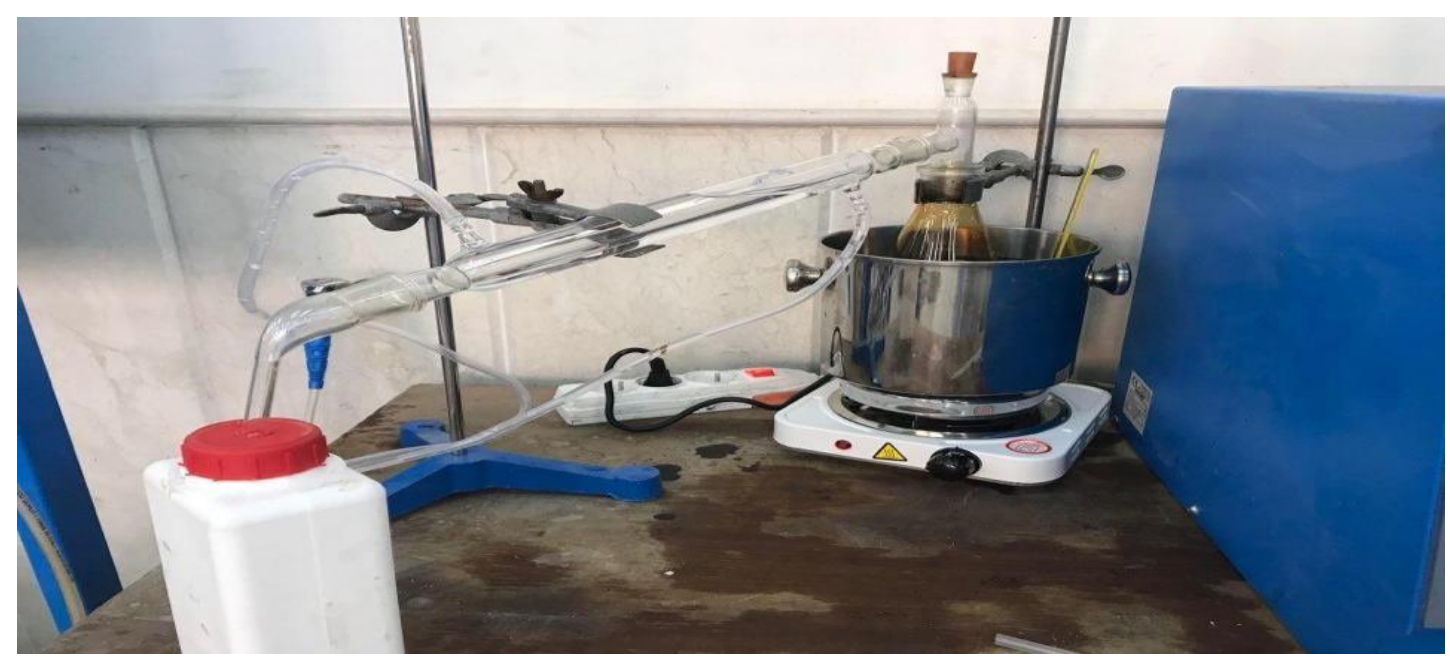

Figure 3. Distillation apparatus 


\section{3- Prep aration the specimens}

Restored aged bitumen were blended with virgin bitumen at rate 20 Percent of bitumen mass at $145^{\circ} \mathrm{C}$ at 1500 -rpm over 30 minutes, as seen in Figure 3. The mixing efficiency of the RAP-virgin and VR was significantly affected Time, temperature with speed. Therefore, the choice among these parameters were dependent on trial - and - error. The research included the mixing of 0 per cent, 2.5 per cent, 5 per cent, 7.5 per cent and 10 per cent of VR material of binder weight with virgin bitumen which included restored bitumen. Optimal rejuvenator dosage that should be added to the combination were determined by softening point, penetration and ductility testing. Table 2 displays the sample symbol by adjusting the VR percentage.

\begin{tabular}{|c|c|c|c|c|c|}
\hline Percentage ( aged bitumen ) + VR & 0 & $2.5 \%$ & $5 \%$ & $7.5 \%$ & $10 \%$ \\
\hline Symbol & 1 & 2 & 3 & 4 & 5 \\
\hline
\end{tabular}

Table 4. symbol percentage

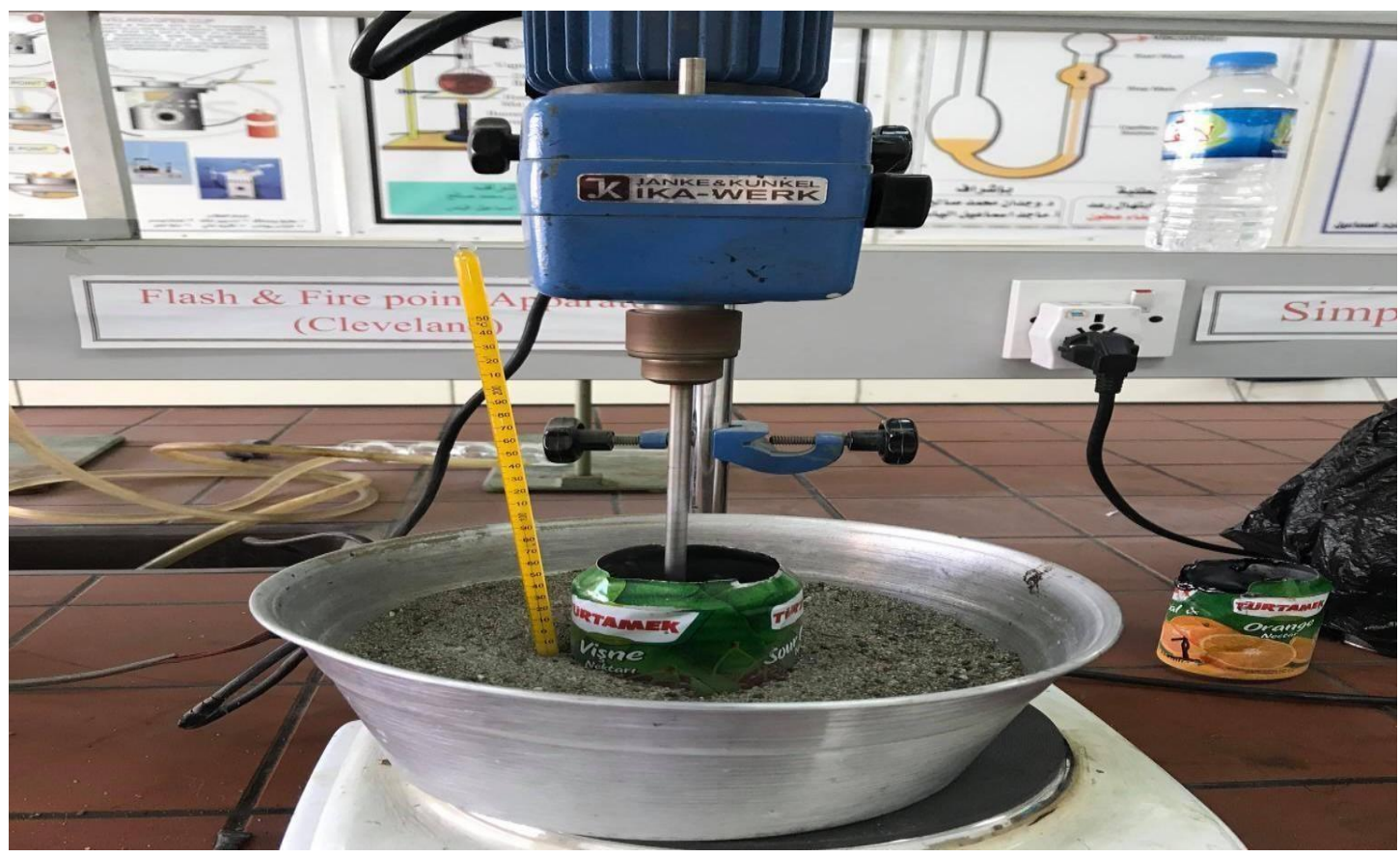

Figure4. bitumen sample mixing

\section{4- Experiments}

\subsection{Penetration test.}

The bitumen penetration value is based on the distance in tenths of mm that a standard needle, under standard test conditions, can vertically penetrate into the bitumen sample. 
may decide the hardness or softness value of bitumen via this test. Throughout this test, heat the bitumen just above softening point. then Pour it over a $15 \mathrm{~mm}$ long tube. Bitumen should be gently stirred to prevent air bubbles. After this cool at room temperature, after this put it for 90 minutes in a water bath. Set the needle to come in contact with the sample surface, then place the container in the penetration device. Make a dial reading zero and drop the needle for precisely 5 seconds, and for that 5 seconds, write down the needle penetration value. Simply repeat the procedure three times and record the average value[16].

\subsection{Softening point.}

The bitumen softening point refers to the point at which the bitumen reaches a certain degree of softening under defined test conditions. Take small quantities of samples of bitumen and heat it up to $75-100 \mathrm{oC}$. In order to perform this test, ring and ball devices are used. Warm the rings to prevent sticking, then spread glycerin. Fill both rings with bitumen and separate the hot sharp knife from the excess material, Assembling the parts of the apparatus, balls are placed in a directed location on the surface of the bitumen sample. And with boiled distilled water, fill the beaker. Then adjust the @ 5oC temperature per minute. This point is noted as a softening point at a certain temperature, bitumen softens and the ball slowly falls downwards and reaches the bottom plate. As per ASTM D36 / D36M.

\subsection{Ductility test}

The bitumen property that enables bitumen to withstand Deformations or elasticity is termed ductility for bitumen. Ductility is determined by the Length in $\mathrm{Cm}$ (centimeter) which the bitumen specimen elongates until it is split when the standard sample is drawn at the appropriate speed and temperature..First of all, The specimen of bitumen is heated and completely melted to $75-100{ }^{\circ} \mathrm{C}$. Then it placed into the assembled brass mold on the plate . Glycerin and dextrin are covered to keep the mold and plate from sticking. After filling the mold, place it for 30-40 min at room temperature, and then place it for 30 minutes in water. Then take it out and use the hot knife to remove the extra amount of bitumen and level the layer. Then put the entire assembly for 85 to 95 minutes in the ductility machine's water bath. Then the brass plate is removed and the mold hooks are attached to the machine and the machine works. [17].

\subsection{Penetration index (PI).}

The penetration results contain a numerical measure of the response of bitumen to temperature differences. Realizing the penetration index of a particular bitumen, its behavior is predicted for application. The method used to calculate the PI is dependent on equation 1:

$$
\mathrm{PI}=\frac{(1951.4-500 \log \mathrm{P}-20 \mathrm{SP})}{(50 \log \mathrm{P}-\mathrm{SP}-120.14)}
$$


The penetration value $(\mathrm{dmm})$ and the softening point value $\left({ }^{\circ} \mathrm{C}\right)$ are denoted by $\mathrm{P}$ and SP in equation 1 , Ok, exactly. A lower PI value means a higher temperature range, with a Value obtained with less than-2 indicated for elevated temperature sensitivity. Usually, old bitumen does have a high PI, suggesting increased brittleness, reduced flow ability and increased vulnerability to cracking.[18]

\section{Results and Discussion}

\subsection{Penetration test}

penetration was carried out to control and rejuvenated asphalt specimens of 0 percent, 2.5 percent, 5 percent, 7.5 percent and 10 percent VR of the total binder by weight. While VR content rises, as shown in Figure 5, penetration increased. More precisely, penetration increased by $8 \%, 18 \%, 26 \%$, and $32 \%$ as the VR content increased by $25 \%$, $5 \%, 7.5 \%$, and $10 \% \mathrm{Ok}$, exactly. One interpretation from these findings is the increase in the proportion of maltene to asphalt and the softening action of the VR as a rejuvenator.

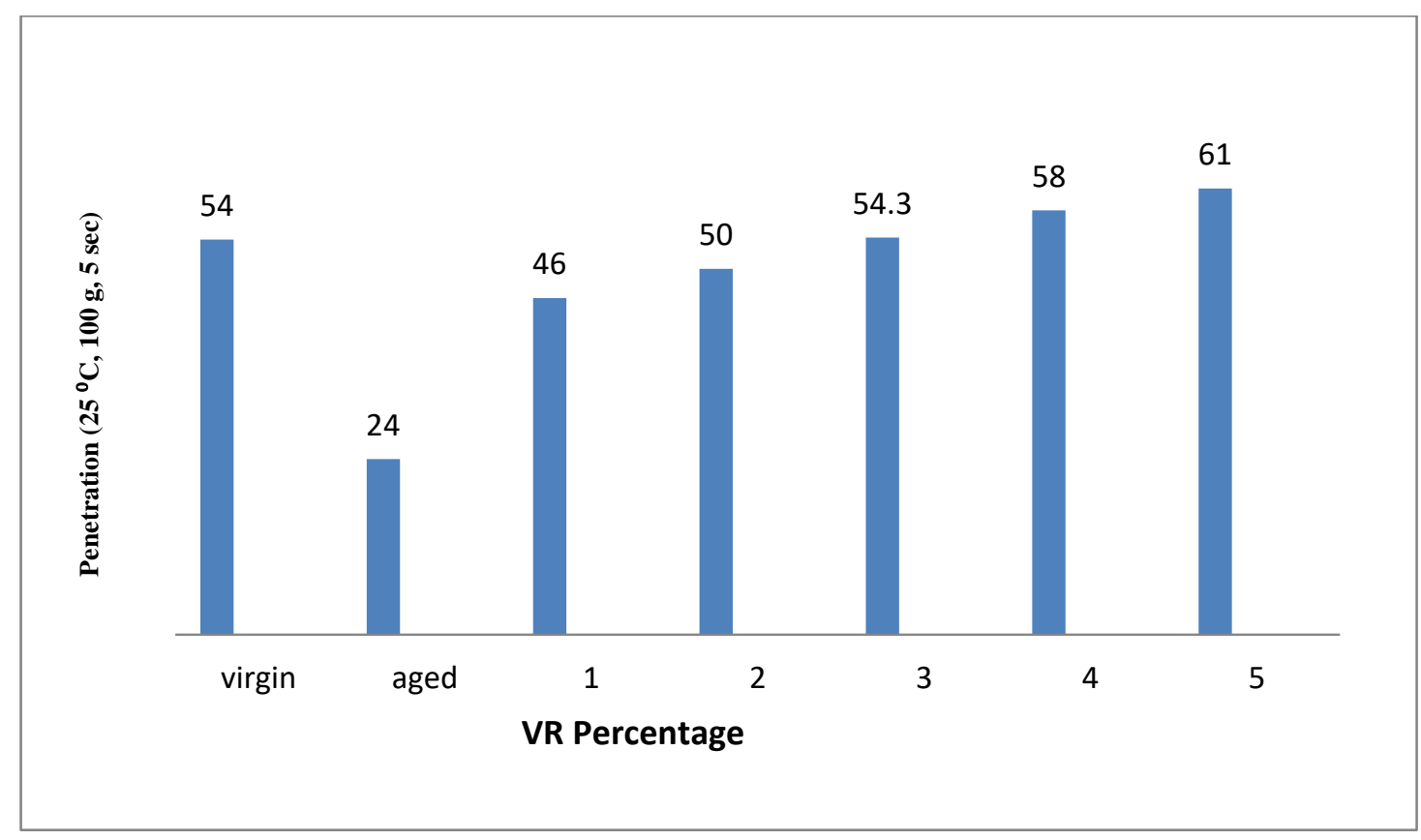

Figure 5. The correlation between penetration and VR percentages

\subsection{Softening point}

Penetration has been implicitly associated with the control binder and bitumen softening point values with VR rejuvenation of 2.5, 5, 7.5 and 10\% (Figure 6). As the concentration of VR raised, the softening point decreased significantly. the 5 percent VR concentration reduced the rejuvenated bitumen softening temperature about $49.25^{\circ} \mathrm{C}$, That is very similar to the $50^{\circ} \mathrm{C}$ virgin bitumen softening stage. The 
degradation for pavement due Due to such a softening point shift, fatigue and lowtemperature cracking were reduced.

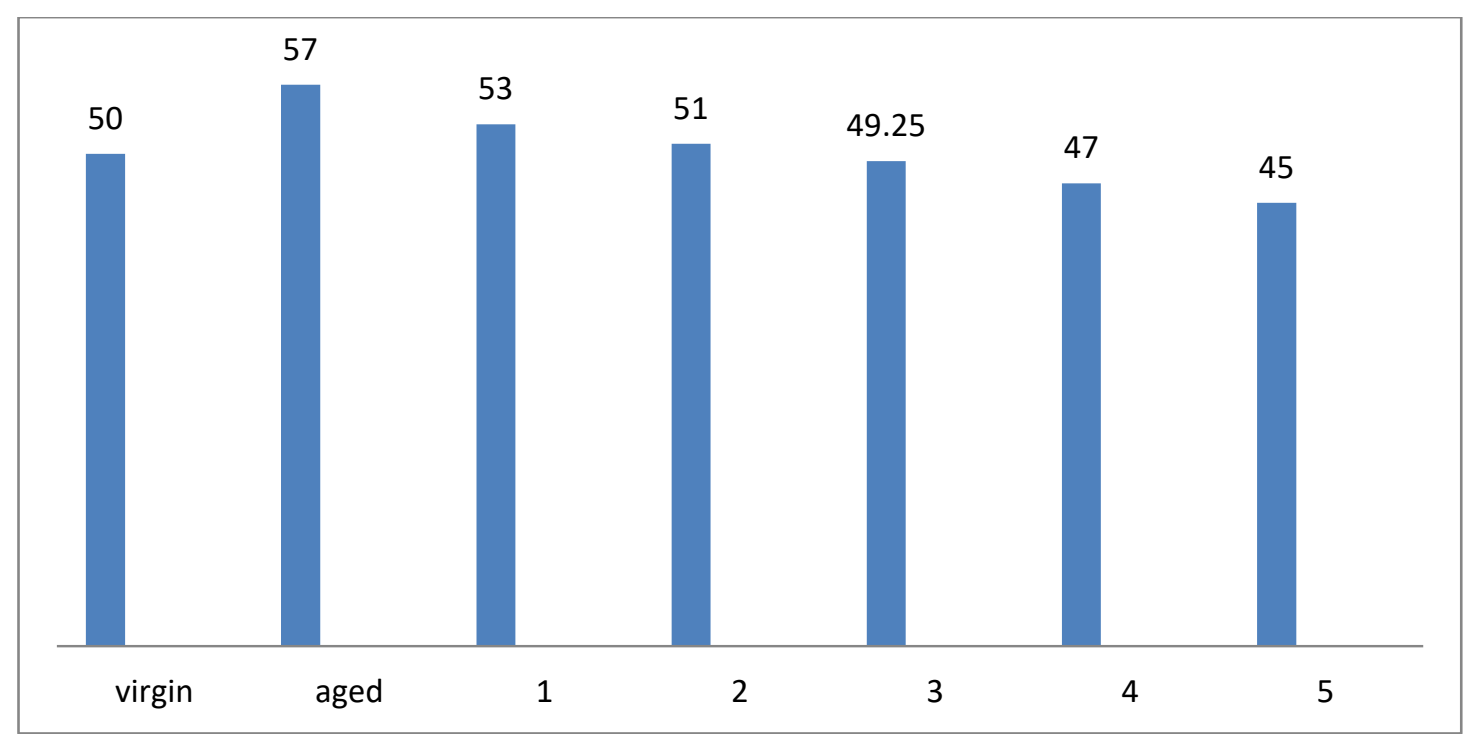

Figure 6. . Comparison between softening point and VR percentages

\subsection{Ductility Test}

The ductility of a bitumen is calculated in $\mathrm{cm}$ by the length it elongates before separating when the material is split by a standard briquette sample at a given speed and temperature. The test were done at temperature degree of $25+0.5^{\circ} \mathrm{C}$, finding that when the VR ratio is increased, ductility increases. This is clearly seen in figure 7 that the ductility increased by 1.1 percent, 5 percent, 5.5 percent, and 6.6 percent as the VR content increased by 2.5 percent, 5 percent, 7.5 percent, and 10 percent respectively.

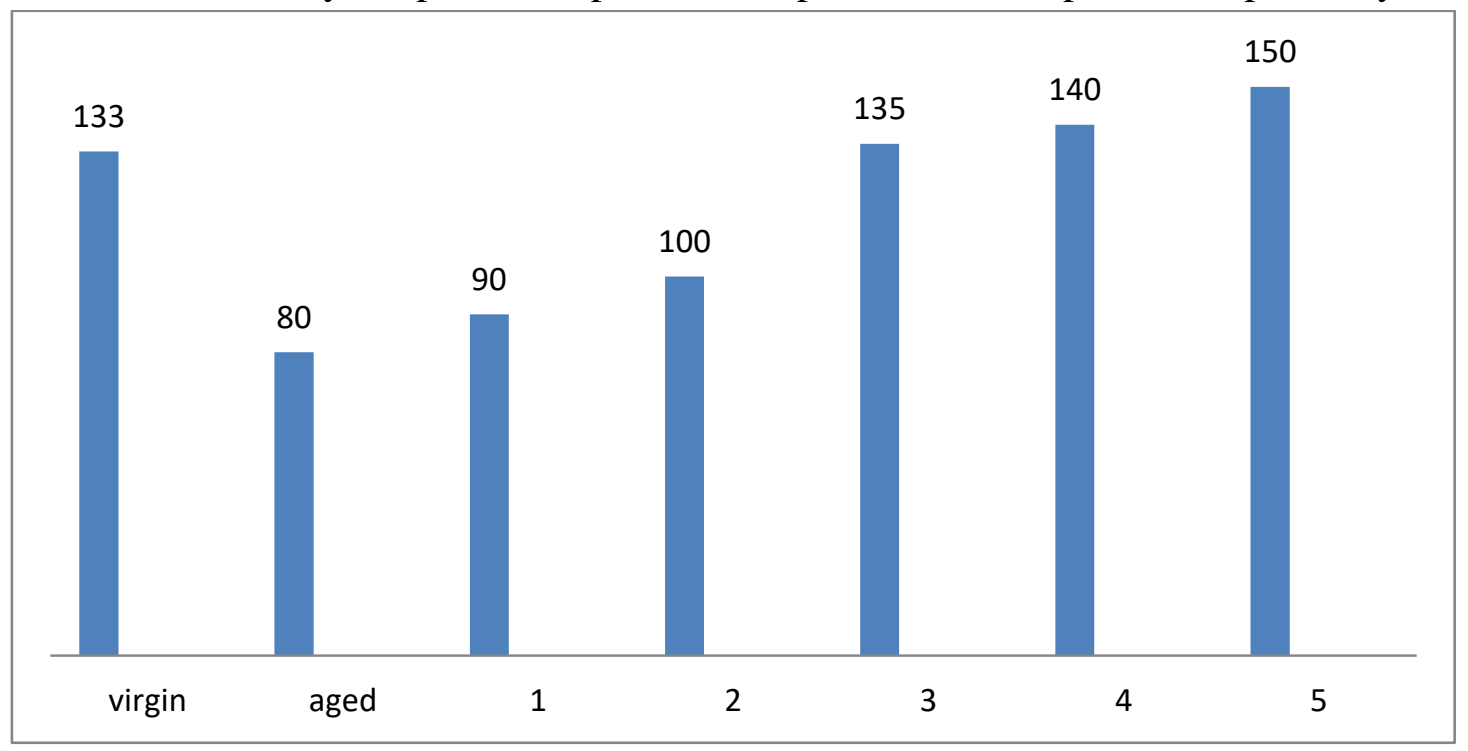

figure 7. correlation between Ductility and VR percentage. 


\subsection{Penetration index (PI)}

All bitumen forms possess thermoplastic properties. So while higher-PI bitumen displays softness which is used in low temperature environments, low-PI bitumen shows stiffness which is used in high temperature areas. Therefore, the behaviour of the different bitumen formulations toward temperature variations is usually quantified by the PI. Usually, aged bitumen does have an enhanced PI, implying enhanced viscosity and decreased brittleness.

\begin{tabular}{|c|c|}
\hline & PI \\
\hline Virgin Bitumen & -1.02 \\
Aged + Virgin = (AV) & -0.66 \\
$(\mathbf{A V})+.25 \%$ VR & -0.95 \\
$(\mathbf{A V})+\mathbf{5 \%}$ VR & -1.197 \\
$(\mathbf{A V})+\mathbf{7 . 5 \%}$ VR & -1.62 \\
$(\mathbf{A V})+\mathbf{1 0 \%}$ VR & -2.092 \\
\hline
\end{tabular}

Table 5. The correlation between PI and VR percentage

\section{Conclusion}

Vacuum residue oil is economically advantageous The reuse and recycling of asphalt is also environmentally sustainable, especially when it has a positive impact on energy consumption and performance As stated earlier, the main objective was to explore the possibility and effects of the rejuvenating agent VR for aged bituminous pavement by evaluating the physical properties of bitumen binders. Use of VR as a rejuvenator at a concentration of 5\% allowed the effective recovery of the Characteristics of aged bitumen. The Penetration was improved but softening point were decreased and the ductility of bitumen was increased when VR was applied to the aged bitumen as a rejuvenator, makes the aged bitumen less viscous. cohesion Third, for the addition of 5\% VR its also reduced PI also, Blending and diffusion will be much faster because it's the same kind, unlike to other kinds of rejuvenators. Because of the variations The physical properties and chemical characteristics of the rejuvenators may have varied impact on the properties of the asphalt binders, It makes logical sense in using VR is therefore the same physical and chemical properties as virgin bitumen. 


\section{References}

[1] J. Ekblad and R. Lundström, "Soft bitumen asphalt produced using RAP,"

Mater. Struct. Constr., vol. 50, no. 1, 2017, doi: 10.1617/s11527-016-0871-z.

[2] F. H. A. FHWA, "Reclaimed Asphalt Pavement in Asphalt Mixtures: State of the Practice,” Rep. No. FHWA-HRT-11-021, no. FHWA, p. McLean, Virginia, 2011, doi: 10.1016/j.proeng.2016.06.119.

[3] M. A. Farooq, M. S. Mir, and A. Sharma, "Laboratory study on use of RAP in WMA pavements using rejuvenator," Constr. Build. Mater., vol. 168, pp. 61-72, 2018, doi: 10.1016/j.conbuildmat.2018.02.079.

[4] V. H. Nguyen, "Effects of laboratory mixing methods and RAP materials on performance of hot recycled asphalt mixtures," p. 226, 2009, [Online]. Available: http://etheses.nottingham.ac.uk/863/.

[5] Z. H. Al Saffar, H. Yaacob, M. K. Idham, M. K. Saleem, J. C. LAI, and R. Putra Jaya, "A review on rejuvenating materials used with reclaimed hot mix asphalt," Can. J. Civ. Eng., pp. 1-39, 2020, doi: 10.1139/cjce-2019-0635.

[6] A. Nosetti, D. Pérez-madrigal, F. Pérez-jiménez, and A. H. Martínez, "Effect of the recycling process and binder type on bituminous mixtures with $100 \%$ reclaimed asphalt pavement," vol. 167, pp. 440-448, 2018, doi:

10.1016/j.conbuildmat.2018.02.042.

[7] Q. F. Fr, S. Quentin, and F. Fr, “( 12 ) Patent Application Publication ( 10 ) Pub . No .: US 2014 / 0033951 A1,” vol. 1, no. 19, 2014.

[8] Z. H. Hussein, H. Yaacob, M. K. Idham, S. Abdulrahman, L. J. Choy, and R. P. Jaya, "Rejuvenation of Hot Mix Asphalt Incorporating High RAP Content : Issues to Consider."

[9] T. B. Moghaddam and H. Baaj, "The use of rejuvenating agents in production of recycled hot mix asphalt: A systematic review," Constr. Build. Mater., vol. 114, pp. 805816, 2016, doi: 10.1016/j.conbuildmat.2016.04.015.

[10] S. Kodippily, G. Holleran, and F. Theunis, "Improving Recycled Asphalt Mix Performance Through Rejuvenation," doi: 10.3141/2575-16.

[11] M. Zaumanis, R. B. Mallick, and R. Frank, "Evaluation of Rejuvenator' s Effectiveness with Conventional Mix Testing for $100 \%$ Reclaimed Asphalt Pavement Mixtures," no. 2370, pp. 17-25, 2013, doi: 10.3141/2370-03. 
[12] J. H. Podolsky, A. Buss, R. C. Williams, N. Hernández, and E. W. Cochran, "Effects of aging on rejuvenated vacuum tower bottom rheology through use of black diagrams , and master curves," Fuel, vol. 185, pp. 34-44, 2016, doi:

10.1016/j.fuel.2016.07.094.

[13] Y. Rasoulzadeh, A. A. Yousefi, and A. Khavanin, "Properties of Modified Bitumen Obtained from Vacuum Bottom by Adding Recycled Waste Polymers and Natural Bitumen," no. March, 2010.

[14] C. Rodezno and G. Julian, "Asphalt Binder Extraction Protocol for Determining Amount \& PG Characteristics of Binders Recovered from Asphalt Mixtures," no. 0092, p. 85, 2018.

[15] Z. H. Hussein, H. Yaacob, M. K. Idham, N. A. Hassan, L. J. Choy, and R. P. Jaya, "Restoration of Aged Bitumen Properties Using Maltenes," IOP Conf.

Ser. Mater. Sci. Eng., vol. 713, no. 1, 2020, doi: 10.1088/1757- 899X/713/1/012014.

[16] P. Apparatus and P. Needle, "Standard Test Method for Penetration of Bituminous Materials 1," vol. i, pp. 4-7, 2006.

[17] B. Statements, "Standard Test Method for Ductility of Bituminous Materials 1," vol. i, pp. 1-4.

[18] O. A. Ehinola, O. A. Felode, and G. Jonathan, "Softening point and Penetration Index of bitumen from parts of Southwestern Nigeria," Nafta, vol. 63, no. 9- 10, pp. 319323, 2012, [Online]. Available:

http://hrcak.srce.hr/index.php?show=clanak\&id clanak jezik=136086. 